\title{
Una museología confinada. El consumo cultural como pasatiempo
}

\author{
Ana Isabel Castro Carbonell | historiadora \\ URL de la contribución <www.iaph.es/revistaph/index.php/revistaph/article/view/4714>
}

Uno de los argumentos que durante la pandemia de Covid-19 se extendió a través de los medios de comunicación tradicionales y los digitales fue que el consumo, en su sentido más amplio, se había detenido. Es evidente que durante las semanas de confinamiento las condiciones sociales y económicas de todo el país se habían alterado hasta el punto de sugerir una verdadera parálisis. Sin embargo, esta idea parece dejar de lado todas aquellas actividades relacionadas con ciertos bienes y servicios, entre ellas, las promovidas por las instituciones culturales.

No cabe duda de que el acto de consumir se encuentra culturalmente mediatizado. Partiendo de esta realidad, las tecnologías de la información han abierto las ventanas a una experiencia museológica supuestamente renovada y más visible enfocada al entretenimiento y disfrute de la ciudadanía. Al mismo tiempo, se han convertido en las máximas responsables de transformar y adaptar los modelos de gestión a la "nueva normalidad", abriendo así el debate de los valores en torno al acceso al conocimiento.

Adoptar una postura reflexiva y humanística en la era del 2.0 nos lleva no solo a considerar el papel que los agentes culturales desempeñan respecto a libertad y democratización dentro de la noción de cultura, sino también a revisar la dimensión misma de lo público. Una museología crítica debe garantizar el derecho al diálogo permanente aun en tiempos de bloqueo. Pero pese a los esfuerzos comunes, ese vínculo ha sido, la mayoría de las veces, improvisado, sustentándose sobre estrategias basadas en el corto plazo. Ello se debe a los constantes cambios que experimentamos casi a diario durante el estado de alarma, pero también a cierto paternalismo por parte de los agentes culturales en relación a las demandas sociales, especialmente las de la llamada generación millennial. En este sentido, creemos necesario señalar tres observaciones que de algún modo influyen en una comunicación que, desgraciadamente, sigue siendo unidireccional.

En primer lugar, es evidente que la capacidad de los museos de conectar con la sociedad se ha visto diezmada y, en el mejor de los casos, limitada a su identidad digital. Eso ha llevado a que se hayan dado situaciones paradójicas, entre ellas que la "apertura real" para muchos solo se haya producido en un contexto en el que el visitante potencial se ha convertido en un ciberusuario. La liberación masiva de contenidos bibliográficos, audiovisuales y catálogos coincide con la imposibilidad de transmitir de otra manera. En principio podríamos pensar que todos estos recursos, entre los que también incluimos los tours virtuales gratuitos, colocarían a las instituciones en una posición ventajosa respecto a otros espacios como las galerías de arte. Pese a ello, aceptar este argumento sin más implicaría reducir la comunicación a una cuestión impersonal, en claro contraste con las actividades fundamentalmente presenciales que se siguen llevando a cabo y que, a todas luces, forman parte de la idiosincrasia de los museos europeos.

En segundo lugar, los museos han venido a ocupar el tiempo libre, entendido durante el confinamiento como una situación a merced de un aburrimiento que debía combatirse a toda costa. El problema en este punto es que la liberación de contenidos se ha enfocado desde la premisa de mantenernos ocupados, que de por sí es una circunstancia temporal, cuando sabemos que el tiempo libre -tiempo del que se dispone-y el ocio-actividad con la que completar dicho intervalo- no son sinónimos, aunque en el lenguaje coloquial se utilicen indistintamente. Se ha intentado crear un acercamiento ligado al 
a debate Hacia una nueva institucionalidad cultural. Modelos emergentes de gestión...

| coordina Jesús Carrillo Castillo

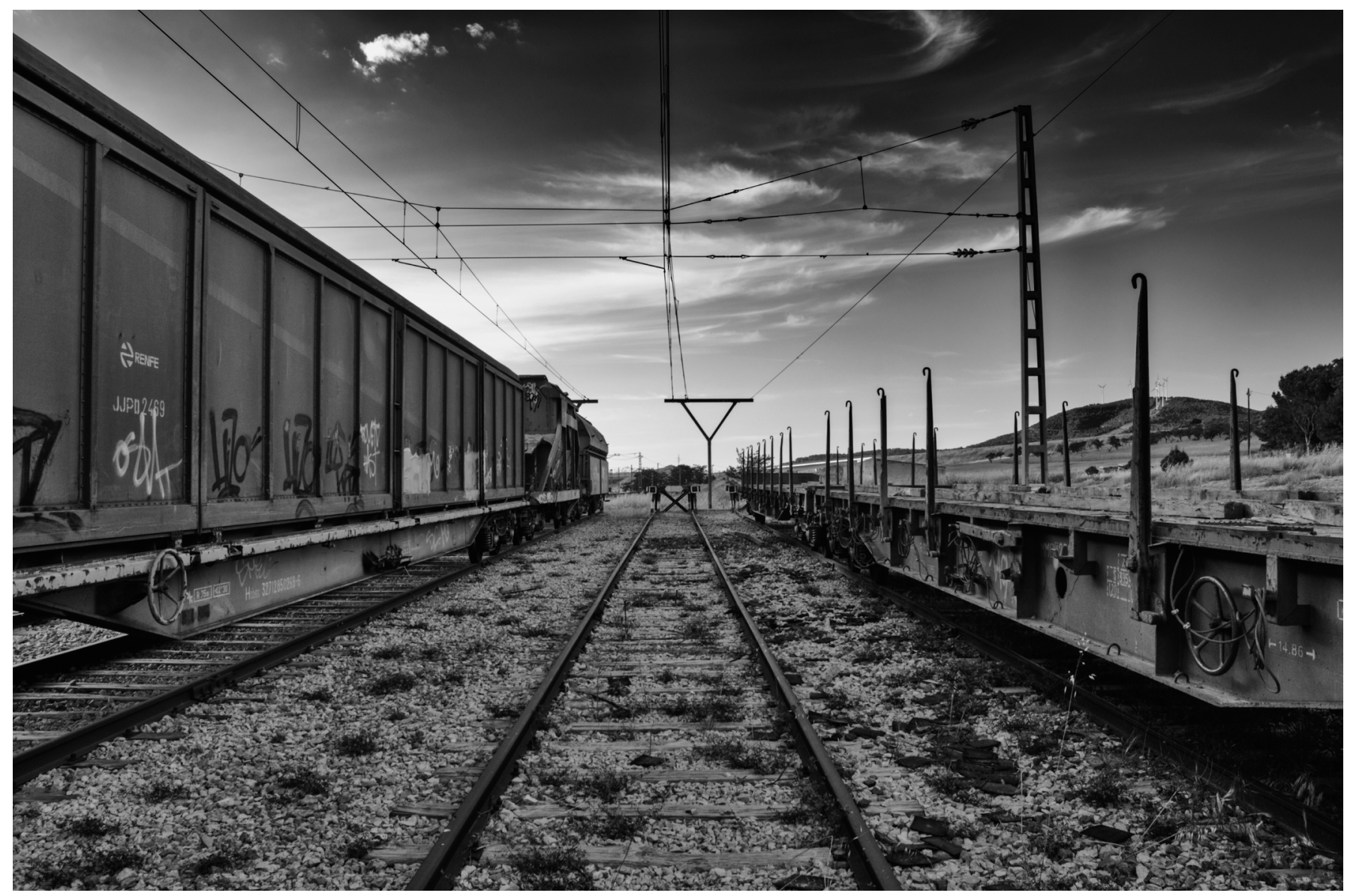

Un mundo en pausa. Estación de La Encina (Villena, Alicante) | foto Iván García Carbonell

despertar de la creatividad y las nuevas aficiones, pero desde un discurso efímero y que no ha tenido cabida cuando los centros han reabierto sus puertas. Satisfecha esa expectativa durante el confinamiento, muchas de esas programaciones on-line han perdido su alcance y popularidad iniciales.

Un tercer tema importante es el de la representación institucional y los modelos de gestión económica post-Covid. En este sentido, estrategias como el mecenazgo o el crowdfunding merecerían más que nunca una oportunidad por reforzar el nexo con la ciudadanía, pero también por contribuir modestamente a la recuperación de los valores éticos en una sociedad en la que se premian el utilitarismo y la inmediatez por encima de otros fines.
Los museos y los centros de arte contemporáneos son los depositarios de la memoria de los pueblos, pero también las coordenadas del nivel de sensibilidad de la sociedad respecto a su porvenir. Por eso se hace tan necesario que participen de los debates públicos sobre la cultura de acceso abierto; que se pregunten cómo y de qué manera los usuarios pueden consumirla activamente. La excepción vivida durante la crisis global que estamos atravesando no puede convertirse en norma. De hacerlo debería aplicarse con prudencia, insistiendo, entre otros aspectos, en la mayor retroalimentación que debe darse entre las instituciones al servicio de la cultura, sus visitantes potenciales y la productividad del tiempo libre. 